\title{
Microstructure and Micro Strain in the CGHAZ of 2.25Cr-1.6W Steel after Intercritical Heat Treatment
}

\author{
Yujing $\mathrm{JIN}{ }^{1) *}$ Jiangping $\mathrm{LIU}^{1)}$ and Wei ZHOU ${ }^{21}$ \\ 1) Precision Manufacturing Engineering Department, Suzhou Institute of Industrial Technology, Suzhou, 215000 PR China. \\ 2) Shagang School of Iron and Steel, Soochow University, Suzhou, 215021 PR China.
}

(Received on May 12, 2017; accepted on August 2, 2017)

\begin{abstract}
Multiple microscopic analysis techniques, such as transmission electron microscope (TEM), electron backscatter diffraction (EBSD) and transmission-EBSD (T-EBSD), were used to study the microstructure and micro strain in the coarse-grained heat-affected zone (CGHAZ) of 2.25Cr-1.6W steel after strain-to-fracture (STF) tests under intercritical heat treatment temperature. This study was a supplement of previous research, which was helpful for understanding the mechanism of reduced susceptibility of reheat cracking by intercritical heat treatment. The result showed that transformation products were retained austenite and twin martensite which had many variants with different crystallographic orientation. Twin boundaries were found both in recrystallized grains and matrix near the recrystallized grains. They were not conventinal parallelling interfaces and the misorientation was not exactly equal to $60^{\circ}$. Transformation resulted in large strain in recrystallized grains and the strain concentration kept away from the prior austenite grain boundaries (PAGBs). Besides transformation strain, the position of recrystallization was another factor which led to different mechanisms of reduced susceptibility to ductility-dip cracking (DDC) in Ni-based alloy and reheat cracking in $2.25 \mathrm{Cr}-1.6 \mathrm{~W}$ steel, respectively.
\end{abstract}

KEY WORDS: recrystallization; intercritical heat treatment; transformation; micro strain; 2.25Cr-1.6W steel.

\section{Introduction}

$2.25 \mathrm{Cr}-1.6 \mathrm{~W}$ steel is developed for high temperature applications such as chemical and fossil fuel power plants. ${ }^{1,2)}$ The weldability is improved by decreasing carbon content to under $0.1 \%$ and economical alloying with $\mathrm{Cr}, \mathrm{Mo}, \mathrm{V}, \mathrm{W}$ and B. The reduction of these elements to a bare minimum guaranteeing creep resistance also decreases the carbon equivalent. ${ }^{3)} 2.25 \mathrm{Cr}-1.6 \mathrm{~W}$ steel exhibits improved weldability and creep rupture strength compared to $2.25 \mathrm{Cr}-1 \mathrm{Mo}$ steel.

The welded joints are typically multipass butt welds and are laid down under conditions of severe structural restraint. The residual stresses are relieved by applying a post-weld heat treatment (PWHT) which involves heating for several hours. ${ }^{4)}$ However, the coarse-grained heat-affected zone (CGHAZ) of $2.25 \mathrm{Cr}-1.6 \mathrm{~W}$ steel has been reported to be susceptible to stress-relief cracking during conventional PWHT. ${ }^{2,5,6)}$

An intercritical heat treatment was employed to reduce the susceptibility of reheat cracking in $2.25 \mathrm{Cr}-1.6 \mathrm{~W}$ steel CGHAZ in our previous study. ${ }^{7)}$ The obtained microstructure is similar with that in the intercritically reheated CGHAZ (IC CGHAZ). That is, partial austenite transformation occurred in the CGHAZ during intercritical heating. It induces reverted austenization. The reverted austenite transforms to various products during subsequent cooling. ${ }^{8)}$

* Corresponding author: E-mail: 00730@siit.edu.cn

DOI: http://dx.doi.org/10.2355/isijinternational.ISIJINT-2017-258
Researches about the transformation products have been reported in various steels. Most of them focus on the effect of transformation products or/and heat treatment parameters on the toughness. ${ }^{9-17)}$ Few reports study the crystallography of the transformation products. ${ }^{8,13)}$ The discussion of the transformation products is seldom analyzed from a different angle.

In our previous study, the effect of recrystallized grain on the misorientation distribution of the prior austenite grain boundaries (PAGBs) was analyzed detailed. The PAGB keeps zigzag configuration after recrystallization, which prevents from cracking along the PAGB and thus reduces the stress-relief cracking susceptibility. Ductility dip cracking (DDC) and reheat cracking are associated with welded fabrication. It is reported that the recrystallization in Ni-based alloy (such as FM52 alloy) effectively reduces the DDC susceptibility. ${ }^{18)}$ In order to supplement the results of previous study, the phase transformation products and micro strain led by recrystallization in the CGHAZ of $2.25 \mathrm{Cr}-1.6 \mathrm{~W}$ steel were analyzed in this study by x-ray diffraction (XRD), optical microscope (OM), scanning electron microscope (SEM), transmission electron microscope (TEM), electron backscatter diffraction (EBSD), and transmission-EBSD (T-EBSD). Moreover, the roles of recrystallization of these two types of cracking were compared.

\section{Experimental Procedures}

The chemical composition of $2.25 \mathrm{Cr}-1.6 \mathrm{~W}$ steel are 
summarized in Table 1. The dimensions of the round bar specimens are shown in Fig. 1. Recrystallization preparation and STF (strain-to-fracture) tests were conducted through the first and second thermal cycle on the Gleeble 3500 thermal-mechanical simulator. Some parameters used are marked in Fig. 1, which has been described in detail in our previous study. ${ }^{7)}$ The specimens were heated to the first and second peak temperature at a rate of $130^{\circ} \mathrm{C} / \mathrm{s}$, holding for $1 \mathrm{~s}$. The interpass temperature was approximately $250^{\circ} \mathrm{C}$. When the STF started, a preload of $\sim 100 \mathrm{MPa}$ was applied to tighten workpiece and ensure that every workpiece had a consistent starting status. The displacement rate was $0.001 \mathrm{~mm} / \mathrm{s}$, which was stated in our previous study. ${ }^{19)}$ The temperatures used in STF tests in this study were 625, 675, and $725^{\circ} \mathrm{C}$.

The cross-section paralleled to the stress axis of failed specimens were mechanically prepared by conventional grinding and polishing techniques, and etched with $4 \%$ nital. The microstructure was examined by OM and SEM. After

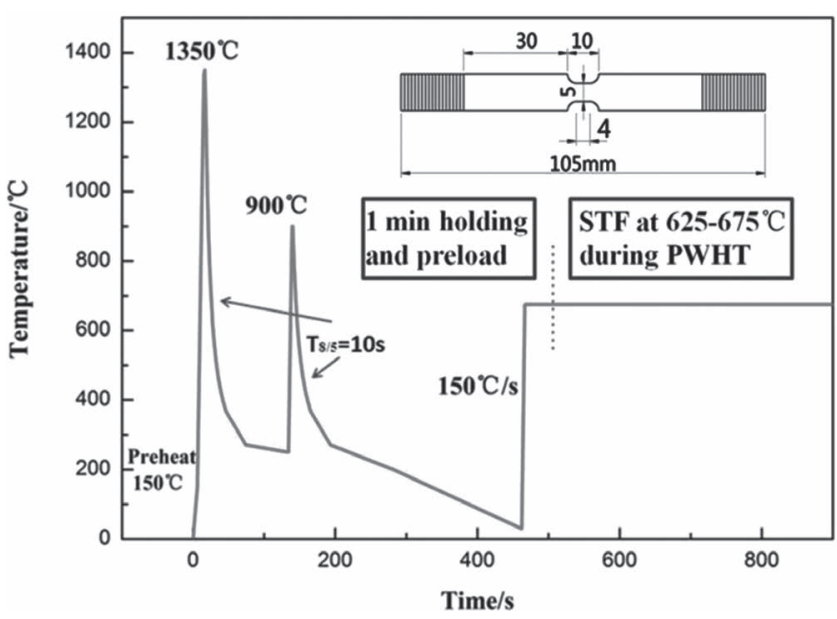

Fig. 1. Schematic illustration of the thermal cycle curves and samples used in this study. the microstructure observation, the samples were polished again, and followed by a vibratory polish with $0.05 \mu \mathrm{m}$ colloidal silica solution. The samples were examined with EBSD technique on a NOVA NanoSEM 230 microscope equipped with an Aztec system under following conditions: acceleration voltage, $20 \mathrm{kV}$; working distance, $10 \mathrm{~mm}$; tilt angle, $70^{\circ}$; spot size, 3 ; step size, $0.01-0.2 \mu \mathrm{m}$.

For T-EBSD scanning, the under condition was followed: $20 \mathrm{kV}$; working distance, $7 \mathrm{~mm}$; tilt angle, $70^{\circ}$; spot size, 3; step size, $0.02 \mu \mathrm{m}$. Channel 5 software from Oxford-HKL was used for the post-processing of orientation data. Thin foils used for T-EBSD were prepared in a twin-jet electropolisher, operated at $50 \mathrm{~V}$, in a solution consisting of $95 \%$ acetic acid and 5\% perchloric acid. The electrolyte temperature was maintained below $-30^{\circ} \mathrm{C}$.

In order to obtain the content of retained austenite, XRD was performed on an X-350A diffractmeter at $25 \mathrm{kV}$ and $5 \mathrm{~mA}$. $\mathrm{Cr} \mathrm{K} \alpha$ radiation was used with a scanning step of $0.1^{\circ}$.

\section{Results and Discussion}

\subsection{Microstructural Characteristics after Intercritical Heat Treatment}

Figure 2(a) shows the partial enlargement version around PAGBs. Blocky transformation products appeared as necklace structure along the PAGBs (marked with red boxes). They distributed unevenly due to the partial recrystallization of austenite. Figure 2(b) shows the phase map in which the red and yellow color corresponding to body-centered and face-centered structures, respectively. A small amount of retained austensite which had face-centered structure was found along the PAGBs and among laths (marked with black circles). XRD was also employed to measure the content of retained austenite in two random locations. The results shown in Table 2 are in agreement with those in Fig. 2(b). The distribution of retained austenite was uneven,

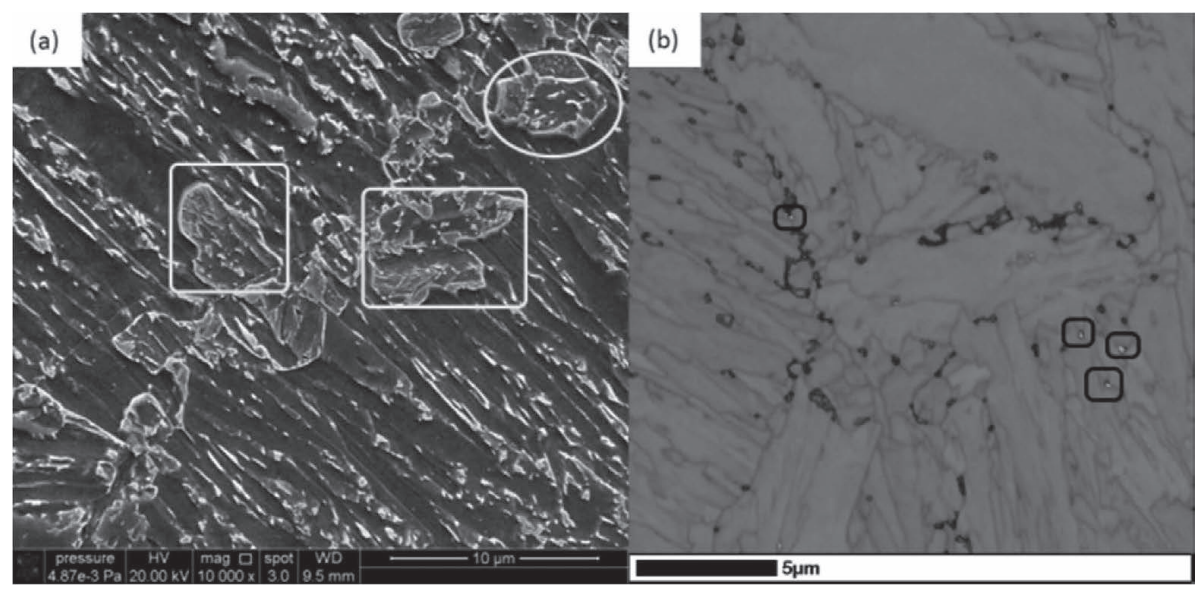

Fig. 2. (a) Scanning microscope photographs around the PAGB after recrystallization; (b) phase distribution map overlaid on the band contrast (BC) map (yellow-austenite, red-bcc martix).

Table 1. Chemical composition (wt $\%$ ) of the $2.25 \mathrm{Cr}-1.6 \mathrm{~W}$ steel.

\begin{tabular}{ccccccccccccccccc}
\hline $\mathrm{C}$ & $\mathrm{Mn}$ & $\mathrm{P}$ & $\mathrm{S}$ & $\mathrm{Si}$ & $\mathrm{Cr}$ & $\mathrm{Mo}$ & $\mathrm{W}$ & $\mathrm{V}$ & $\mathrm{Nb}$ & $\mathrm{N}$ & $\mathrm{Al}$ & $\mathrm{B}$ & $\mathrm{Ni}$ & $\mathrm{Ti}$ & $\mathrm{Ti} / \mathrm{N}$ \\
\hline 0.06 & 0.37 & 0.012 & 0.002 & 0.28 & 2.32 & 0.08 & 1.56 & 0.22 & 0.044 & 0.0035 & $<0.015$ & 0.0026 & 0.05 & 0.009 & 3.9 \\
\hline
\end{tabular}


which was in relation with the transformation sequence of different areas.

It is worth nothing that points without being indexed appear black in Fig. 2(b). It resulted from great transformation strain and small size of transformation products. This could be explained by the results in Fig. 3, which shows TEM and EBSD results of recrystallization. A typical recrystallized grain occupied the two images. During the TEM examination, it was observed that the diffraction pattern of the recrystallized grain was too difficult to be obtained and indexd. Meanwhile, large area of black points occurs around the recrystallized grains in Fig. 3(b). From the results obtained from Figs. 2(b) and 3(b), it could be deduced the phase transfomation of recrystllization leads to large strain concentration in the recrystallized grains. The large strain concentration affected the data collection during EBSD scanning and TEM examination. As a result, these zones appeared with black points in EBSD results. As can be seen, the TEM and EBSD results both reflected great transformation strain led by recrystallization. In addition, TEM and EBSD results showed that there were many micro grains (also namely variant ${ }^{8,20)}$ ) in recrystallized grain, which had different crystallographic orientation, size, and shape. In addition, even probable twin substructure is found in Fig. 3(a).

\subsection{Substructure Study of Recrystallization by T-EBSD}

T-EBSD had higher resolution and nearer work distance than conventional EBSD. The scanning step was then reduced. Meanwhile, the TEM specimens were thin and benefit for lattice relaxation. T-EBSD has successfully indexed deformed metal of nanocrystal and even small precipitates. ${ }^{21)}$ Therefore, the substructure analyses

Table 2. XRD results of retained austenite.

\begin{tabular}{ccccc}
\hline$\Psi$ & \multicolumn{2}{c}{ Location 1} & \multicolumn{2}{c}{ Location 2} \\
\hline Phase & $\alpha$ & $\gamma$ & $\alpha$ & $\gamma$ \\
$2 \theta \mathrm{p}$ & 156.136 & 128.527 & 156.149 & 128.700 \\
Integral intensity & 19679.6 & 246.3 & 20358.8 & 147.2 \\
Content of austenite & \multicolumn{2}{c}{$4.8 \%$} & \multicolumn{2}{c}{$2.8 \%$} \\
\hline
\end{tabular}

of recrystallized grain were performed by T-EBSD. The results are shown in Fig. 4. In Fig. 4(a), two recrystallized grains (marked with white dotted line) in which the variants with different crystallographic orientation are completely indexed. The phase distribution map in Fig. 4(b) shows that retained austenite marked with yellow color in the black box locates among variants. Figure 4(c) shows the $\Sigma 3$ boundaries distribution in recrystallized grains and matrix nearby. Combining with the misorientation distribution results by line-method marked with black lines in Fig. 4(a), it can be found that the $\Sigma 3$ boundaries in this study are not conventinal parallelling interfaces and the misorientation is not exactly equal to $60^{\circ}$ (as seen in Figs. 4(d) and 4(e)).

The crystallographic results of transfromation products in low carbon steel showed that crystallographic packet in martensite owned this type of twin boundary. ${ }^{22,23)}$ In addtion, the island enriched in $\mathrm{C}$ was the most plausible site for the retained austenite. Therefore, the recrystallized grains were high carbon twin martensite and retained austenite, which had also been proved in some researches. ${ }^{24-26)}$ The twin substructure belonged to transformation inducing twinning due to supercooled austenite transformation to martensite at low temperature. ${ }^{27)}$

\subsection{Micro Strain Analysis}

Figure 5 shows the kernel average misorientation (KAM) and strain contouring map with different magnification in order to reflect the strain concentration in recrystallized grains and prior austenite grains. The KAM value was used to describe the strain concentration. Combining with Figs. 4(a) and 5(a), it is found that green colored zones which represent large KAM value exist along the recrystallized grain boundaries. The large KAM value corresponded to a high local strain level. It was known that the location of cracking depended on the local strain level which led to strain concentration rather than average strain distribution. $^{28)}$ Therefore, the partial recrystallization would lead to redistribution of local strain. As seen in Fig. 5(b), the strain contouring map provides an estimate of deformation, or strain, in individual grains in a map. The component measures the maximum misorientation between any 2 points in a grain and then weights this grain according to this misorientation value. According to the packet size of the steel,

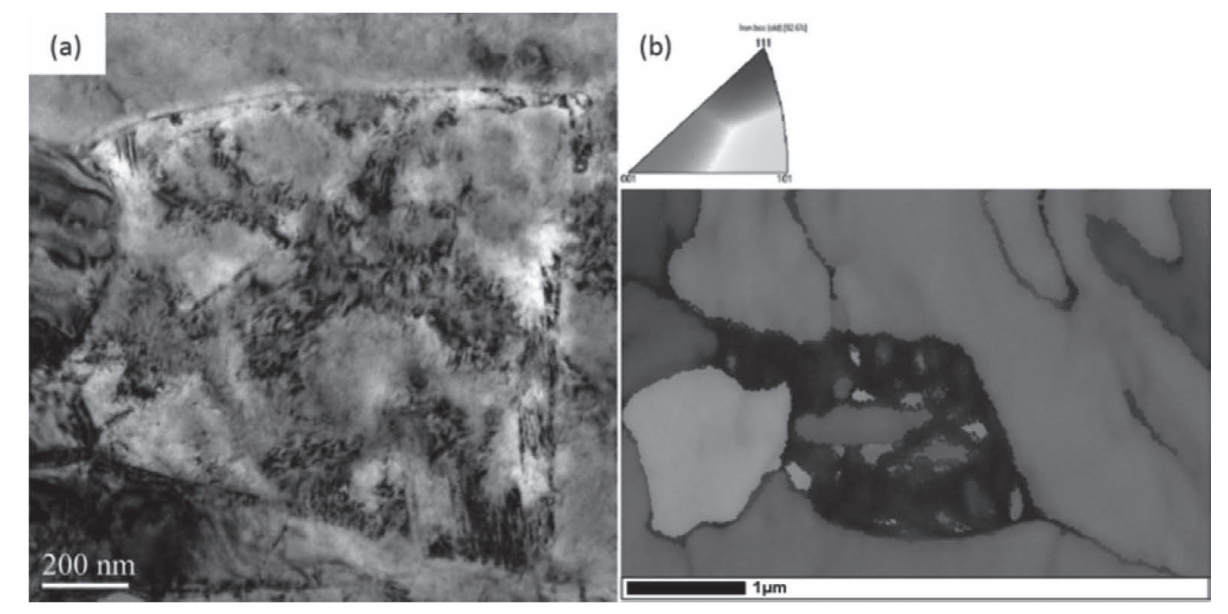

Fig. 3. (a) TEM; and (b) EBSD analyses of recrystallized grain. 


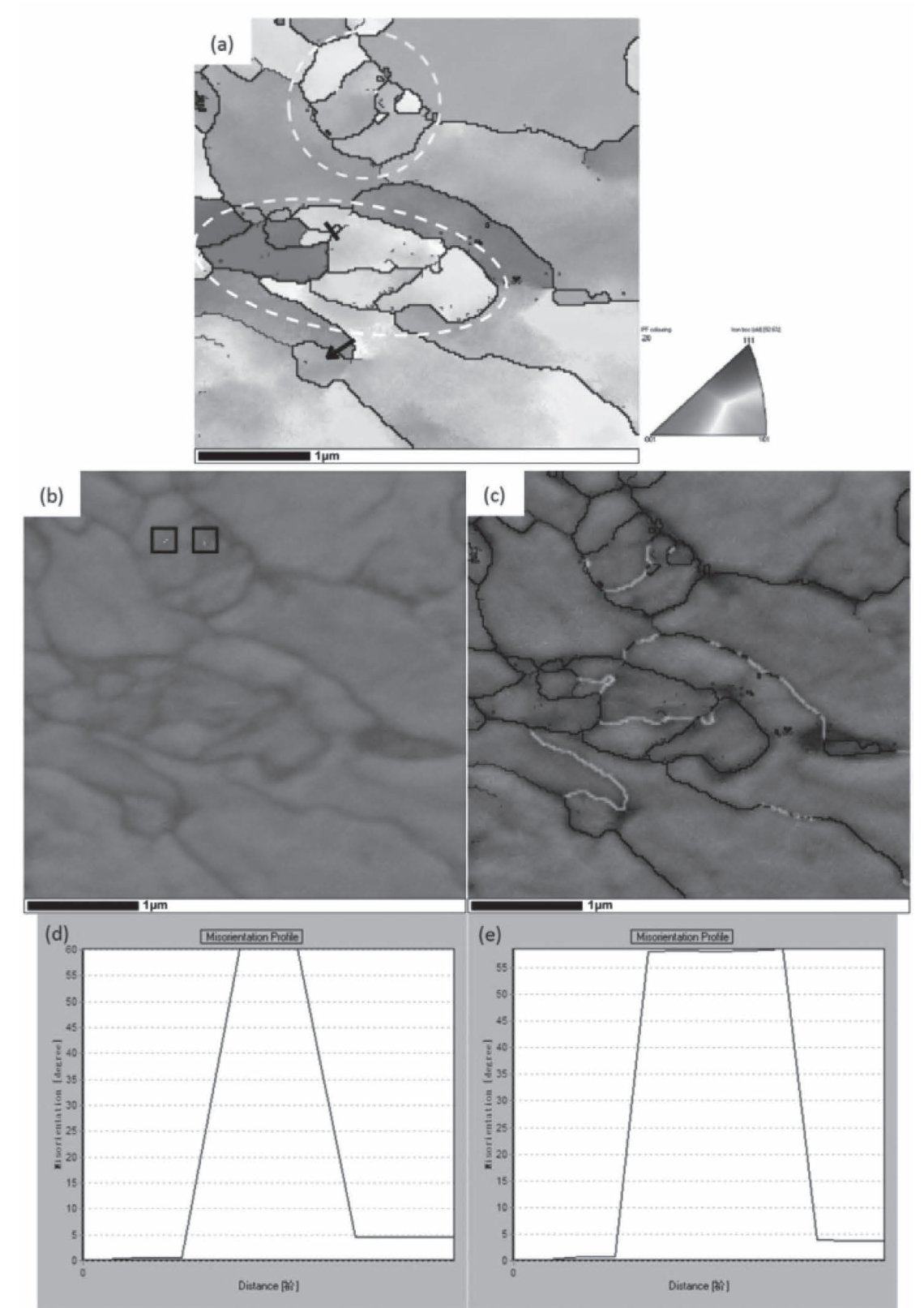

Fig. 4. T-EBSD results of recrystallized grains (a) IPF map; (b) phase distribution map (red-bcc, yellow-fcc); (c) $\Sigma 3$ boundaries (red line) distribution map; (d) misorientation distribution of straight line in (a); (e) misorientation distribution of arrowed line in (a).

(a)

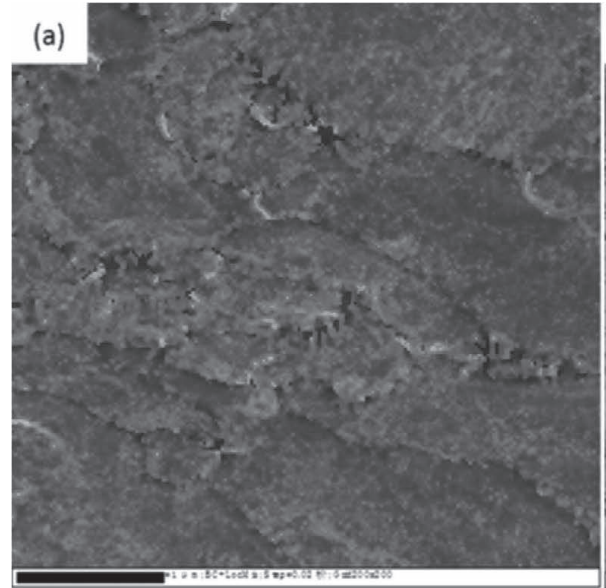

$$
\frac{\operatorname{Min}}{0} \quad \frac{\max }{3.5}
$$

(b)

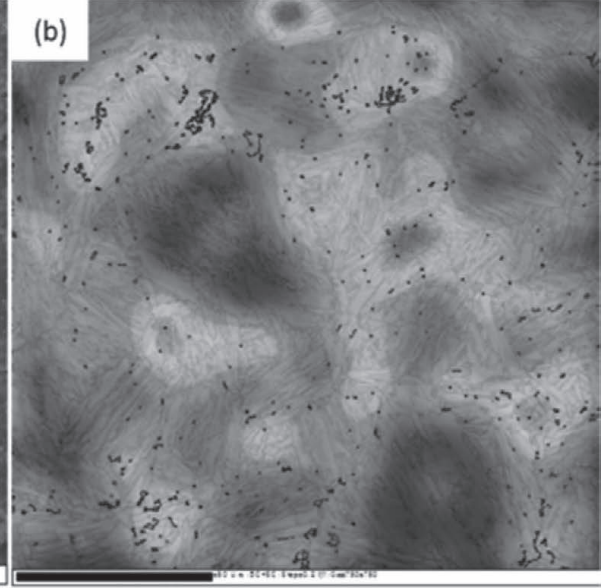

$\underset{0}{\operatorname{Min}} \quad \operatorname{Max}$

Fig. 5. (a) KAM; and (b) strain contouring map overlaid on the BC map. 
10 was selected as the the half-width to obtain a smooth appearance map. From the results obtained from Figs. 2(b) and 3(b), the black points in the EBSD results corresponded to the locations of transformation products in Fig. 5(b). The similar condition had been also found by Inoue et al. ${ }^{29)}$ It was found that the extent of deformation was various among different grains. It was led by the recrystalization. Obviously, the black points which located at this zone with large strain could verify this.

\subsection{Analyzing the Role of Recrystallization in Two Dif- ferent Materials Systems}

Though recrystallization had been reported to effectively reduce the high temperature cracking susceptibility in Ni-based alloy ${ }^{18)}$ and heat resistant steel, ${ }^{7)}$ the mechanisms might be different. In this section, these two different materials systems were compared. Inconel 690 welded joint after $1050^{\circ} \mathrm{C}$ heat treatment in reference 18 and $2.25 \mathrm{Cr}-1.6 \mathrm{~W}$ CGHAZ after $725^{\circ} \mathrm{C}$ heat treatment were selected as representative objects of these two materials systems. Figure 6 shows the IPF maps obtained from references 18 and 7 . The IPF maps indicated the location of recrystallization and cracking. By comparison, the position and strain of recrystallization were the main factors which affected the cracking mechanisms of different materials systems. Firstly, the position of recrystallization was different. As shown in Fig. 6(a), recrystallized grains in Inconel 690 alloy form at the triple junctions of the austenite grains. By contrast, they form along PAGBs and distribute unevenly in $2.25 \mathrm{Cr}-1.6 \mathrm{~W}$ steel (as shown in Figs. 2 and 6(b)). Secondly, the transformation products were austenite in Inconel 690 alloy while they were martensite and retained austenite in $2.25 \mathrm{Cr}-1.6 \mathrm{~W}$ steel. Therefore, the transformation strain was larger in recrystallized grains of $2.25 \mathrm{Cr}-1.6 \mathrm{~W}$ steel. These two factors led to different cracking characteristics. In Inconel 690 alloy, strain concentrated at austenite grain boundaries, ${ }^{18)}$ which led to the crack nucleated at austenite grain boundaries and propagated to the triple junctions. In $2.25 \mathrm{Cr}-1.6 \mathrm{~W}$ heat resistant steel, strain concentrates at newly former recrystallized grain boundaries (Fig. 2(b)). Additionally, coarser precipitates formed at these high angle boundaries. ${ }^{7)}$ Therefore, the crack in the CGHAZ of $2.25 \mathrm{Cr}-1.6 \mathrm{~W}$ steel tended to nucleate and propagate along these newly former recrystallized grain boundaries. As could be seen, the recrystallization increased the tortuosity of cracking path in both materials. The tortuosity was resulted from many small recrystallized grains at the triple junction in Inconel 690 alloy while it was resulted from unevenly distributed recrystallized grains along the PAGBs in $2.25 \mathrm{Cr}-1.6 \mathrm{~W}$ steel.

Figure 7(a) provides the schematic diagram of the recrystallized grains along the PAGB corresponding to that in Fig. 2(b), which has been described in our previous study. ${ }^{7}$ Three types of recrystallization, namely Type I, Type II and Type III, along the PAGBs are defined according to the relationship between the newly formed grain boundaries and the PAGBs. ${ }^{7}$ For Type I, none of the newly formed grain boundaries overlap with the PAGBs. For Type II, only a part of the newly formed grain boundaries overlap with

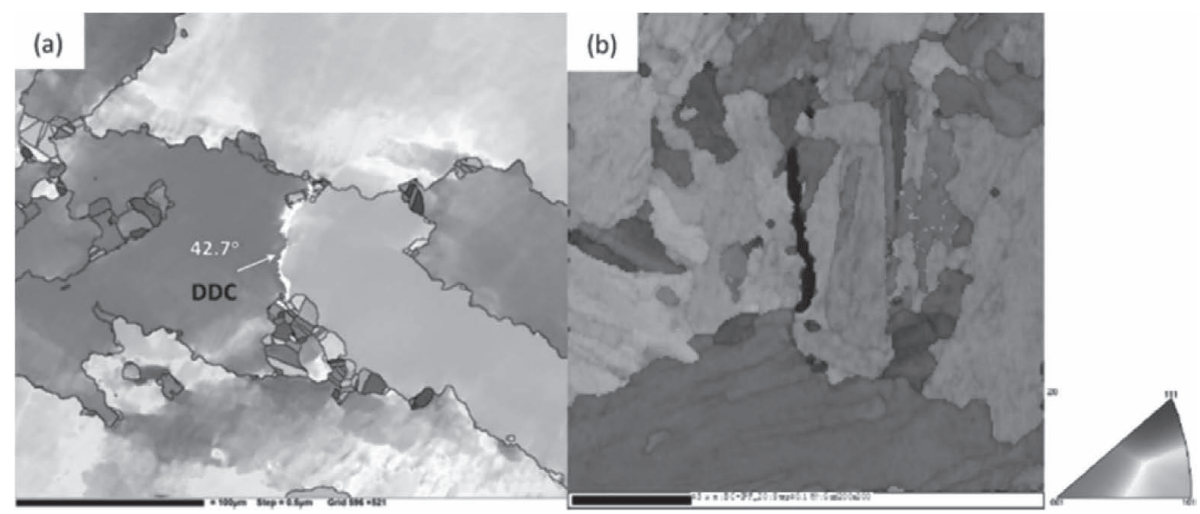

Fig. 6. IPF maps of (a) DDC in Inconel 690 alloy; ${ }^{18)}$ and (b) reheat cracking zones in $2.25 \mathrm{Cr}-1.6 \mathrm{~W}$ steel. ${ }^{7)}$

(b)

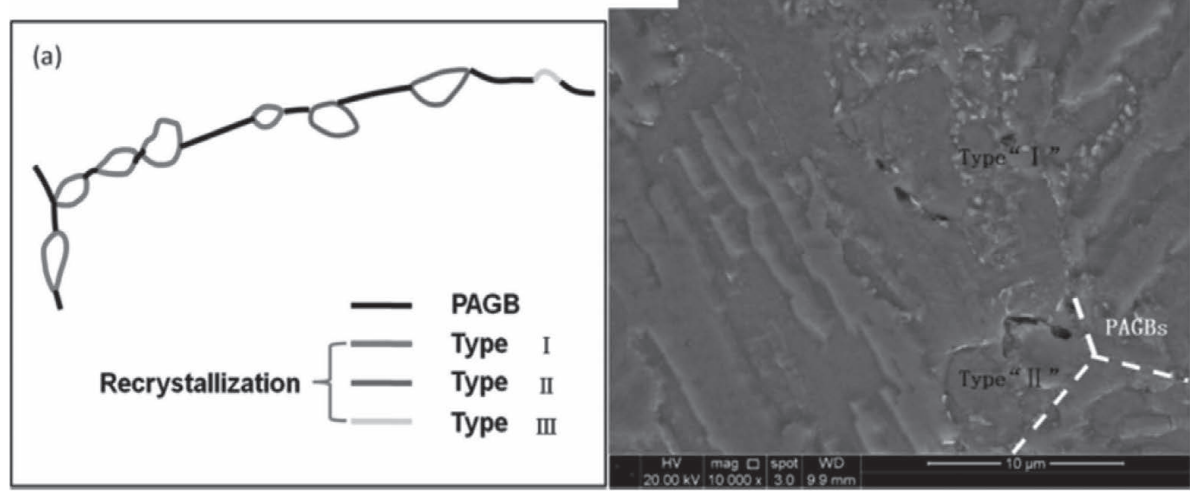

Fig. 7. (a) Schematic diagram showing the location and type of the recrystallization along the PAGB; ${ }^{77}$ (b) SEM images of type "I" and type "II" recrystallized grains at the PAGBs. 


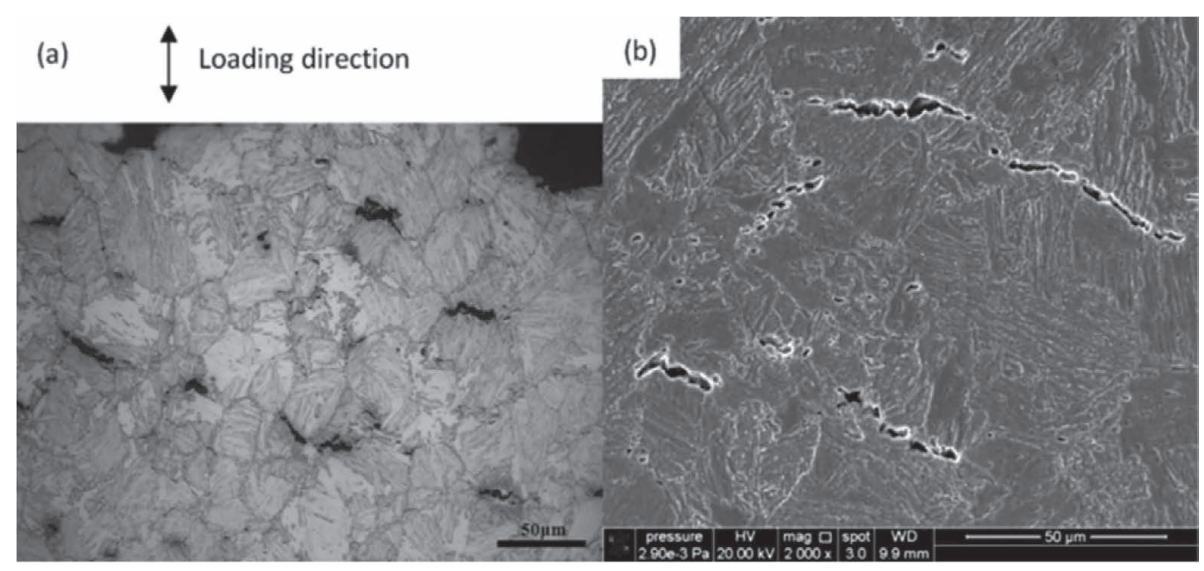

Fig. 8. (a) OM; and (b) SEM images of the cross-sections at $625^{\circ} \mathrm{C}$.

the PAGBs. When the overlapped part in Type II doesn't exist, such recrystallization is named as Type III. Figure 7(b) shows the location of cavities at the grain boundaries of type "I" and type "II" recrystallized grains. These cavities existed at newly formed recrystallized grain boundaries rather than PAGBs. It demonstrated the reason why the cracking propagation was inhibited and the susceptibility of reheat cracking was reduced.

The cross-sectional area beneath the fracture surface of the STF specimen was investigated in order to verify the results above. One set of results is given in Fig. 8. Many secondary cracks could be seen behind the fracture surface with each being approximately normal to the direction of the applied tensile stress. The cracks were wavy like and along the PAGBs, which was in accordance with the results obtained from the strain maps.

\section{Conclusions}

(1) Blocky transformation products appear as necklace structure along the PAGBs. Transformation products have many micro grains which are also named as variants. These micro grains have different crystallographic orientation.

(2) $\Sigma 3$ boundaries (twin boundaries) exsit at the boundaries of recrystallized grains and martix neary. They are not conventinal parallelling interfaces and the misorientation is not exactly equal to $60^{\circ}$.

(3) The transformation products are retained austenite and twin martensite, which results in large strain in recrystallized grains and the strain concentration keeping away from the PAGBs.

(4) The mechanisms of reduced susceptibility of DDC in Ni-based alloy and reheat cracking in heat resistant steel by recrystallization are different. The position and strain of recrystallization are the main factors. In Inconel 690 alloy, strain concentrates at austenite grain boundaries, which leads to the crack nucleates at austenite grain boundaries and propagates to the triple junctions. In $2.25 \mathrm{Cr}-1.6 \mathrm{~W}$ steel, strain concentrates at newly former recrystallized grain boundaries. Additionally, coarser precipitates form at these high angle boundaries. Therefore, the crack in the CGHAZ of $2.25 \mathrm{Cr}-1.6 \mathrm{~W}$ steel tends to nucleate and propagate along these newly formed grain boundaries after intercritical heat treatment.

\section{Acknowledgement}

This work was supported by the financial support of the National Natural Science Foundation of China (Grant No. 51401139) and Top-notch Academic Programs Project of Jiangsu Higher Education Institutions (PPZY2015B186) and scientific research start-up funding of suzhou institute of industrial technology.

\section{REFERENCES}

1) Y. Sawaragi, T. Kan, Y. Yamadera, F. Masuyama, T. Yokoyama and N. Komai: Proc. 6th Int. Conf. on Materials for Advanced Power Engineering, Springer International Publishers, Switzerland, (1998), 61.

2) J. G. Nawrocki, J. N. Dupont, C. V. Robion and A. R. Marder: Weld. J., 79 (2000), 355

3) P. Mohyla and J. Koukal: Acta Metall. Slovaca, 9 (2003), 210.

4) J. Pilling and N. Ridley: Metall. Trans. A, 13A (1982), 557.

5) J. G. Nawrocki, J. N. Dupont, C. V. Robion and A. R. Marder: Weld. $J ., 80$ (2001), 18.

6) J. G. Nawrocki, J. N. Dupont, C. V. Robino, J. D. Puskar and A. R. Marder: Weld. J., 82 (2003), 25.

7) Y. Jin, Y. Li, K. Wang, M. Xu, J. Chen, J. Xu and H. Lu: Mater. Sci. Eng. A, 633 (2015), 42.

8) Y. You, C. Shang, L. Chen and S. Subramanian: Mater. Des., 43 (2013), 485.

9) Y. S. Ahn, H. D. Kim, T. S. Byun, Y. J. Oh, G. M. Kim and J. H. Hong: Nucl. Eng. Des., 194 (1999), 161.

10) L. Shi, Z. Yan, Y. Liu, C. Zhang, Z. Qiao, B. Ning and H. Li: Mater. Sci. Eng. A, 590 (2014), 7.

11) C. L. Davis and J. E. King: Metall. Mater. Trans. A, 25 (1994), 563.

12) C. L. Davis and J. E. King: Metall. Mater. Trans. A, 27 (1996), 3019.

13) T. Tsuchiyama, M. Natori, N. Nakada and S. Takaki: ISIJ Int., 50 (2010), 771

14) P. Tao, H. Yu, Y. Fan and Y. Fu: Mater. Des., 54 (2014), 914.

15) P. Mohseni, J. K. Solberg, M. Karlsen, O. M. Akselsen and E. Østby: Mater. Sci. Tech-Lond., 28 (2012), 1261.

16) V. G. Haugen, B. R. S. Rogne, O. M. Akselsen, C. Thaulow and E. Østby: Mater. Des., 59 (2014), 135.

17) J. Kang, C. Wang and G. D. Wang: Mater. Sci. Eng. A, 553 (2012), 96.

18) J. Q. Chen: Ph.D. thesis, Shanghai Jiao Tong University, (2014), 72.

19) Y. Jin, H. Lu, C. Yu and J. Jin: Mater. Charact., 84 (2013), 216.

20) G. Miyamoto, N. Takayama and T. Furuhara: Scr. Mater., 60 (2009), 1113.

21) S. Suzuki: JOM, 65 (2013), 1254.

22) H. M. Flower and T. C. Lindley: Mater. Sci. Tech-Lond., 16 (2000), 26.

23) P. Yang, F. Lu, L. Meng and W. Mao: Acta Metall. Slovaca, 45 (2009), 1409.

24) P. Mohseni and J. K. Solberg: Metall. Mater. Trans. A, 45 (2014), 384.

25) K. Ikeuchi, J. Liao, H. Tanabe, K. Nakai and Y. Ohmori: ISIJ Int., 35 (1995), 1203

26) M. Vladimir, Z. Li and O. Hitoshi: Trans. JWRI, 20 (1991), 69.

27) Z. C. Liu, H. P. Ren and S. L. An: The Martensite Phase Transformation, Science Press (China), Beijing, (2012), 1

28) Y. Jin and H. Lu: ISIJ Int., 55 (2015), 308

29) T. Inoue, F. Yin and Y. Kimura: Mater. Sci. Eng. A, 466 (2007), 114. 